\title{
Towards Safer and More Sustainable Ways for Exploiting Nuclear Power
}

\author{
Wolfgang Kröger, Didier Sornette, Ali Ayoub \\ Department of Management, Technology and Economics (D-MTEC), ETH Zurich, Zurich, \\ Switzerland \\ Email: kroeger@ethz.ch
}

How to cite this paper: Kröger, W., Sornette, D. and Ayoub, A. (2020) Towards Safer and More Sustainable Ways for Exploiting Nuclear Power. World Journal of Nuclear Science and Technology, 10, 91-115. https://doi.org/10.4236/winst.2020.103010

Received: May 15, 2020

Accepted: June 14, 2020

Published: June 17, 2020

Copyright $\odot 2020$ by author(s) and Scientific Research Publishing Inc. This work is licensed under the Creative Commons Attribution International License (CC BY 4.0)

http://creativecommons.org/licenses/by/4.0/

\begin{abstract}
Future electricity systems are challenged by deep decarbonization and concurrently increasing demand and there are growing concerns that renewables cannot shoulder this alone. Starting from the proven principle of diversity, we argue for keeping the nuclear option open or even for expanding its use. However, the perspectives are dim for the current technology as safety concerns and social aversion remain as fundamental problems. While looking for future revolutionary safe and more sustainable nuclear concepts we first review the main characteristics of civil nuclear energy, as well as its safety records and technical progress. We then list the key requirements for innovative nuclear systems designs which are less dependent on active safety systems and human performance as well as social stability. This allows us to provide a concept by concept comparison and assessment of existing and novel technologies and designs including different coolants and neutron spectra. The results indicate a high potential for far-reaching improvements compared to most advanced LWRs, although none of the candidate concepts meets all requirements convincingly, yet, helium cooled, small modular reactors (HTR-PM) come closest. We end by stressing the need for future research and development, and keeping human capital and know-how in nuclear energy; we call for an urgent increase in government and international RD\&D funding by the order of a few hundreds of billions of USD per year, which will likely lead to breakthroughs that will restart productivity growth in severely affected stagnating modern economies.
\end{abstract}

\section{Keywords}

Low-Carbon Energy Systems, Sustainability, Nuclear Safety, Safety Requirements, Advanced Reactor Concepts, SMR, RD\&D Needs 


\section{Introduction}

Availability of energy is key for the well-being of our societies and economies. The intensive use of electricity, in particular, has enabled the $3^{\text {rd }}$ and $4^{\text {th }}$ industrial revolutions; the latter is ongoing with the progressive fusion of the natural and digital world. By the end of 2018 [1] the worldwide primary energy consumption totaled to $166378.8 \mathrm{TWh}$, has doubled within the last 50 years and increased by $2.9 \%$ compared to 2017. Almost $40 \%$ are converted into electricity which corresponds to a share $16 \%$ of the final energy demand. The annual energy consumption per capita varies strongly by country and region; $20 \%$ of the global population consume $80 \%$ of the global energy, and roughly 1.3 billion people have no access to electricity. Scenario analyses predict a massive growth of primary energy, mainly driven by developing countries, to cope with the expected increase of world population and to expand energy access and economic opportunities to billions of people. The electricity sector is expected to grow disproportionally, e.g. by a factor of 2.5 till 2050 [2], in particular to penetrate domains other than the traditional ones, i.e. e-mobility, digitalization, buildings, industries. Moreover, electricity will be needed in concentrated forms to power future mega-cities-another mega-trend [3].

This challenging trajectory is simultaneously confronted to the consensus that anthropogenic $\mathrm{CO}_{2}$ emissions must be drastically reduced, requiring the decarbonization of the energy systems which are currently relying on fossil fuels with about $84.7 \%$ [1]. The electricity production, currently based at about $38 \%$ on coal, $23.2 \%$ on gas and $2.8 \%$ on oil, contributes almost $30 \%$ to the global carbon emissions of 33,891 million tons (which increased by $2 \%$ compared to 2017). Therefore, the electricity sector needs to play a central role in any transition to a deeply de-carbonized energy system; a new mix and roughly doubled share of low-carbon electricity generation assets by 2050 is required to meet the " $2^{\circ} \mathrm{C}$ target" for global warming, while other sustainability indicators like use of land and other resources, affordability, waste production, factorial and perceived risks, and so on, must be kept in mind.

Most scenario-based projections (see also [4], Chapter 1.3.1) and strategies of countries focus on expanded use of renewables. Besides hydroelectricity with a share of roughly $15 \%$, wind and solar contributed $9.3 \%$ of the global power production (18.7\% in Europe) in 2018, with a $14.5 \%$ annual growth, slightly below its historical average; China contributed $45 \%$ of the global growth in renewable power generation. However, there are growing concerns about whether 1) renewable generation will grow sufficiently fast, with the need for it to grow more than twice as quickly than it actually did [1], 2) variable energy sources alone, depending on weather, daytime and season, will be adequate and sufficiently secure and 3) the required infrastructure including storage, upgraded grids and flexible backups can be provided. Diversification seems to be a prudent principle.

Nuclear power is regarded as a promising asset in a de-carbonized, more sustainable energy system. Currently, nuclear power contributes $10.15 \%$ to global elec- 
tricity production-varying by countries/regions, 23\% in Europe. The share increased from about $2 \%$ in 1971 to $18 \%$ in 1998 , decreased afterwards but grew in 2018 by $2.4 \%$, the fastest growth since 2010 , to which China contributed almost three quarters [1]. However, the prospects of nuclear power are dim in many parts of the world, with costs [5], lack of public acceptance and some unresolved issues including disposal of high-radioactive waste as key problems [4]. Prominent studies regarding future shares of electricity production by nuclear energy are ambiguous and vary significantly-from zero ([6], by input requirement) to a grow by $28 \%$ till 2040 [2] — the latter corresponds to additional $510 \mathrm{GWe}$, and raises questions of commercial deployment readiness as well as industrial and regulatory capabilities.

In a nutshell, a transition to a deep de-carbonized and more sustainable electricity sector will require of a mix of generation assets, including nuclear energy while advanced technology options are necessary to overcome existing barriers against its extended, even expanded use.

\section{Characteristics of Nuclear Power}

The use of nuclear power has proven to be a mature technology. In 2019 [7], there was a fleet of 450 reactor units with 398.9 GWe total net installed capacity in operation, distributed throughout 31 countries. Experience accumulated to roughly 17,000 reactor-years. The mean capacity factor of the operating units was $80 \%$ [8], which supplied 2701.4 TWh of electricity or a share of $10.15 \%$ of worldwide electricity production [1]. Currently, there are 54 new units under construction with 57.4 GWe capacity in 20 countries, with China taking the lead with 11 units (11) [9]. In 2019, 6 new reactors were commissioned while 13 reactors were permanently shut down, including 5 units in Japan. New builds in the Western world are rare and, like the EPR in Finland and France, confronted with serious costs and construction time overruns (tripled) while projects in Asia tend to stay within basic conditions.

Currently, $80 \%$ of all operating nuclear reactors are light water reactors (LWR), which use low enriched uranium (3\% - 5\% U235). Uranium has incomparably high energy density compared to other energy carriers; the energy density of a mix of natural non-fissile $\mathrm{U} 238$ and $\mathrm{Pu} 239$ used in breeder reactors is approximately $80,620,000 \mathrm{MJ} / \mathrm{kg}$, or 3.55 million times higher than black coal, meaning that, while undergoing full breeding and fission, one $\mathrm{kg}$ of uranium is the equivalent of burning 3,500 tons of black coal [4]. This high energy density also simplifies the storage and transport of nuclear fuel.

An essential aspect is the continuous availability of uranium and long-lasting confirmed reserves. According to [10], the total yearly consumption of uranium is approximately 63,000 tons. Considering that the current proven reserves in the low-cost range extraction (up to US\$130/kgU) are about 6.1 million tons and higher-cost range extraction (up to US\$260/kgU) total at 7.9 million tons, the world can produce enough uranium for the next 125 years. When consider- 
ing the inferred and reasonably assured resources, the total reserves are estimated to be around 15.9 million tons, enough for 254 years of operation, all with the current rate of consumption. Additionally, assured reserves for uranium are higher than what is considered normal for most minerals, indicating that further exploration will most likely lead to new deposits, albeit at a higher cost. Furthermore, increased energy efficiency and higher burn-up, moving to advanced nuclear options including breeder reactors, using thorium (three to four times more abundant in the Earth's crust), application of new uranium mining and extraction technologies, and so on, could theoretically place nuclear as a practically unlimited resource.

Currently, nuclear power is the second largest source of global low-carbon energy, behind hydro. Broadening the view to the "three pillars of sustainability", i.e. the environmental, economic and social dimension, a detailed study was done in the EU-Project NEEDS [11], where 26 advanced electricity generation technologies were analyzed and compared using 36 technology-specific evaluation criteria and indicators. Nuclear options were ranked top, given equal weighting of the three dimensions. In particular, current nuclear technology has very low greenhouse gas emissions, comparable to the renewable energy sources (considering the whole life cycle). By 2050, with the deployment of generation IV reactors, the emissions are estimated to decrease further, potentially making nuclear power the cleanest form of energy, see Figure 1. On the other side, giving higher weight on the social dimension and focusing on radioactive wastes, land contamination due to hypothetical accidents, risk aversion and perception issues, terrorist threats and conflict potential, the ranking changes to the disadvantage of nuclear energy, see also [4].

Nuclear power is not without its drawbacks, however, both in the physical process and current technologies. The physical process of nuclear fission generates a surplus of neutrons, radioactive decay heat producing fission products

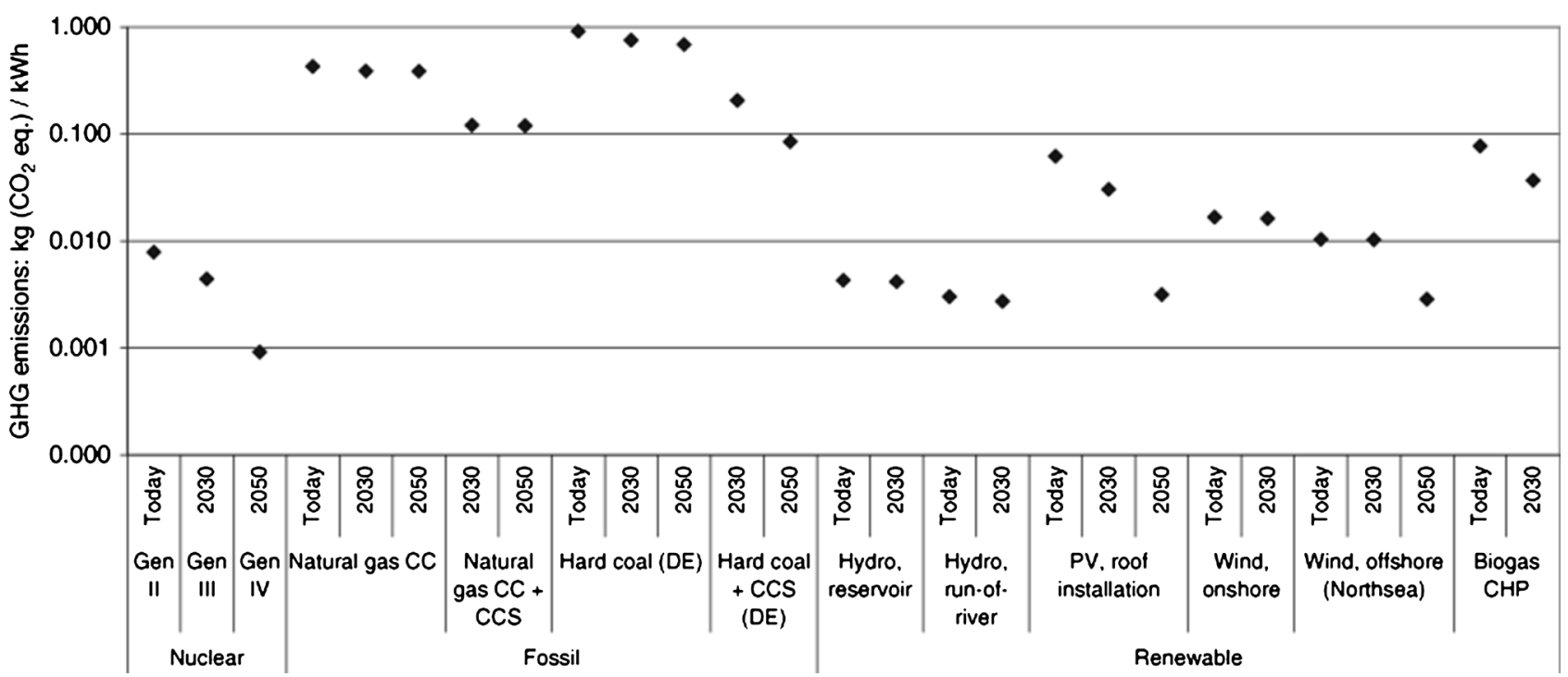

Figure 1. Greenhouse gas emissions of selected technologies at different time periods [12]. 
and high-level nuclear waste. This leads to major design challenges, implementation of safety functions and development of demanding strategies for operation and decommissioning of nuclear power plants as well as for management and storage of nuclear waste. Current technologies address these issues successfully. However, certain aspects are still problematic, such as meltable fuel cladding, reliance on active safety systems and early operator actions, vulnerable structural material, and little grace time in case safety systems fail. Large radioactive releases cannot be excluded despite their rarity, would a beyond-a-design-basis accident happen in today's large-scale nuclear power plants with high power density.

An assessment of various technologies with regard to operational risk and maximum potential fatalities in the event of a severe accident was also performed as part of the NEEDS project [11]. The results show fossil technologies with the highest operational risks, while nuclear is close to the PV and wind. However, nuclear has the highest number of potential fatalities in the event of a severe accident, in addition to the long-term contamination of the affected area, leading to a very high level of risk aversion by the general public and strong opposition, especially in the Western world. As a consequence, some western projects have been delayed or cancelled, while some countries have decided to completely phase out nuclear power due to the public pressure and reduced cost-effectiveness. Contrary to this, the public opposition is far less pronounced in Asia and nuclear power is largely accepted as a viable option.

Many developing countries would greatly benefit from the use of nuclear energy (especially in Africa). However, they face some fundamental problems on their path of adopting nuclear technology. The development of small modular reactors might provide a solution to some of the problems, considering the potential safety and cost-effectiveness of these reactors.

Nuclear energy has the potential to play a major role in a diversified, de-carbonized/more sustainable future energy mix. However, safety concerns, social acceptance and costs remain fundamental problems.

\section{Safety Records and Technical Progress}

Throughout its long operational history, the civil nuclear industry has stood as a unique, reliable, and clean source of energy. Nevertheless, it had witnessed numerous operational disruptions ranging from anomalies, incidents up to near-misses, and even major accidents, that have all been well recorded by regulators and international organizations. Herewith, we will focus on three core disruptive events [4], for a comprehensive list and analysis of safety-relevant events see [13].

1) The first was the Three Mile Island PWR unit 2 (TMI-2) partial meltdown in the United States on March 23, 1979, initiated by a loss of main feed water transient during full power operation. Emergency feed water system was unavailable due to a testing and maintenance error. To relieve the increasing reac- 
tor pressure, the pilot-operated relief valves (PORVs) opened, yet failed to reclose, leading to large losses of primary coolant. Operators were not aware of what was going on due to inadequate valve instrumentation; they tripped the automatic safety injection systems, actuated on the low reactor water level, thinking they were inadvertently actuated. The core was already uncovered by the time the next-shift operators realized the situation and re-established the coolant injection. Nevertheless, they managed to minimize the offsite consequences and contained the fission product within the containment.

2) The second was the accident at Chernobyl RBMK unit 4 in the former Soviet Union on April 26, 1986. Operators disabled several safety systems (including several control rods withdrawal) in order to perform a safety test on the capacity of the turbine generator to supply emergency power during its rundown. Several operator errors in addition to inherent design flaws (such as positive reactivity coefficients and a positive scram effects due to control rod graphite tip) resulted in unstable power conditions and ultimately led to a power excursion followed by destruction/meltdown of the core, an uncontrollable graphite burning and large release of fuel and radioactive substances; the plant had no reinforced containment building. 28 workers/firemen died directly after the accident and several further deaths were recorded, 4000 people are estimated to have prematurely died from radiation in the neighboring countries.

3) The third accident happened on March 11, 2011 in Japan. A beyond design 9.0 - 9.2 seaquake hit the Fukushima Daiichi nuclear power plant, consisting of six BWR units, causing a reactor SCRAM and total loss of offsite power. While the structural damage to the plant was very limited, the following $14-14.5 \mathrm{~m}$ tsunami flooded the onsite emergency diesel generators causing an extended blackout at units $1-4$. Three units experienced core meltdown with hydrogen buildups and explosions. Large amounts of radioactive substances were released and tens of thousands of people evacuated. Health effects were psychological rather than physical, and the huge number of casualties (more than 18,500 people) is due to the natural disaster caused by the quake and tsunami.

The accidents were not specific to a single nation or a particular reactor type but have stressed several common safety deficits and concerns. In addition to random equipment failures and occurrence of initiating events, the non-technical contributions (human, organizational, societal, safety culture) have been clearly present at multiple levels in all the serious nuclear events. At the plant level, operator and testing \& maintenance errors have been evident, either by creating/aggravating the scenario, or by failing to mitigate the consequences. At the operating company level, there was a tendency to hide safety deficits and inherent design flaws, in addition to overlooking potential beyond design situations. At the regulatory and political level, there were institutional deficits and conflicts of interests. Moreover, the accidents have demonstrated the importance of an adequate safety culture, training and communication and knowledge transfer across all levels. Other practical lessons were realizing the importance of post 
core-damage provisions in minimizing the accident consequences, namely, containment filtered venting systems and offsite emergency measures.

These major accidents, even though they did not result in many direct casualties, yet have had huge economic and financial consequences, including health costs and physical losses, as well as contamination, decommissioning, evacuations, and others, see ([4], Chapter 5.3) for more details. This created a public view that nuclear energy is dreadful, amplified by the association with nuclear bombs and wars, the fear of invisible radiations, and the problem of nuclear waste [14]. This "dread factor" is rooted deep down in the human mindset of overestimating the risk of "low probability-high consequence events". Nevertheless, for a genuine risk appraisal, one has to have a correct entanglement of both probability of an accident and its consequences. Probabilistic Safety Analysis (PSA) is the standard framework used for analyzing risk in nuclear power plants at three sequential levels. It helps identifying accident scenarios, estimating their probabilities/frequencies, as well as their consequences. PSA level 1 studies and quantifies core damage frequency (per reactor-year, CDF). PSA level 2 describes the containment response and quantifies the radioactive release frequencies (large early release frequency, LERF). PSA level 3 characterizes the environmental and public consequences that are important for evacuation and emergency planning [15].

The most developed level is level 1, being concerned with modeling reliability of in-plant engineered safety systems and their demands during postulated initiating events, hence faced by less uncertainties and beyond-plant unknowns. CDF estimates for operating (Generation II) LWRs are between $10^{-4}$ to $10^{-5}$ per reactor-year and can be as low as $10^{-6}$ for Gen III and some retro-fitted Gen II plants [4]. To see how these model results represent reality, a first estimate could be using core meltdown events in the nuclear power sector. Five core melt-down events have occurred during roughly 17,000 reactor-years of operation (counting Fukushima multi-unit meltdown as 3 occurrences). Therefore, an empirical estimate for core damage frequency of operating LWR will be around $3 \times 10^{-4}$ per reactor-year, which is not so far from the PSA CDF results. However, this estimate is based on a very limited sample size due to the-fortunately-rare occurrence of core damage events, and does not account for safety improvements over time. A better estimate could be calculated while expanding the sample size and considering accident precursors that are quantified by a conditional core damage probability (CCDP), i.e. probability of core damage knowing that this precursor has happened, and this is calculated using the relevant part (chain) of the PSA models. To have an idea of the operational fleet safety performance, the USNRC Accident Sequence Precursor (ASP) program [16] have trended the so-called "integrated ASP index" for the US fleet over time, which serves as an empirical proxy of CDF. It is defined as the sum of precursors CCDPs identified in a given year, normalized by the total operating years for all US reactors in that year. Figure 2 shows that a more recent and a more representative statistical CDF 


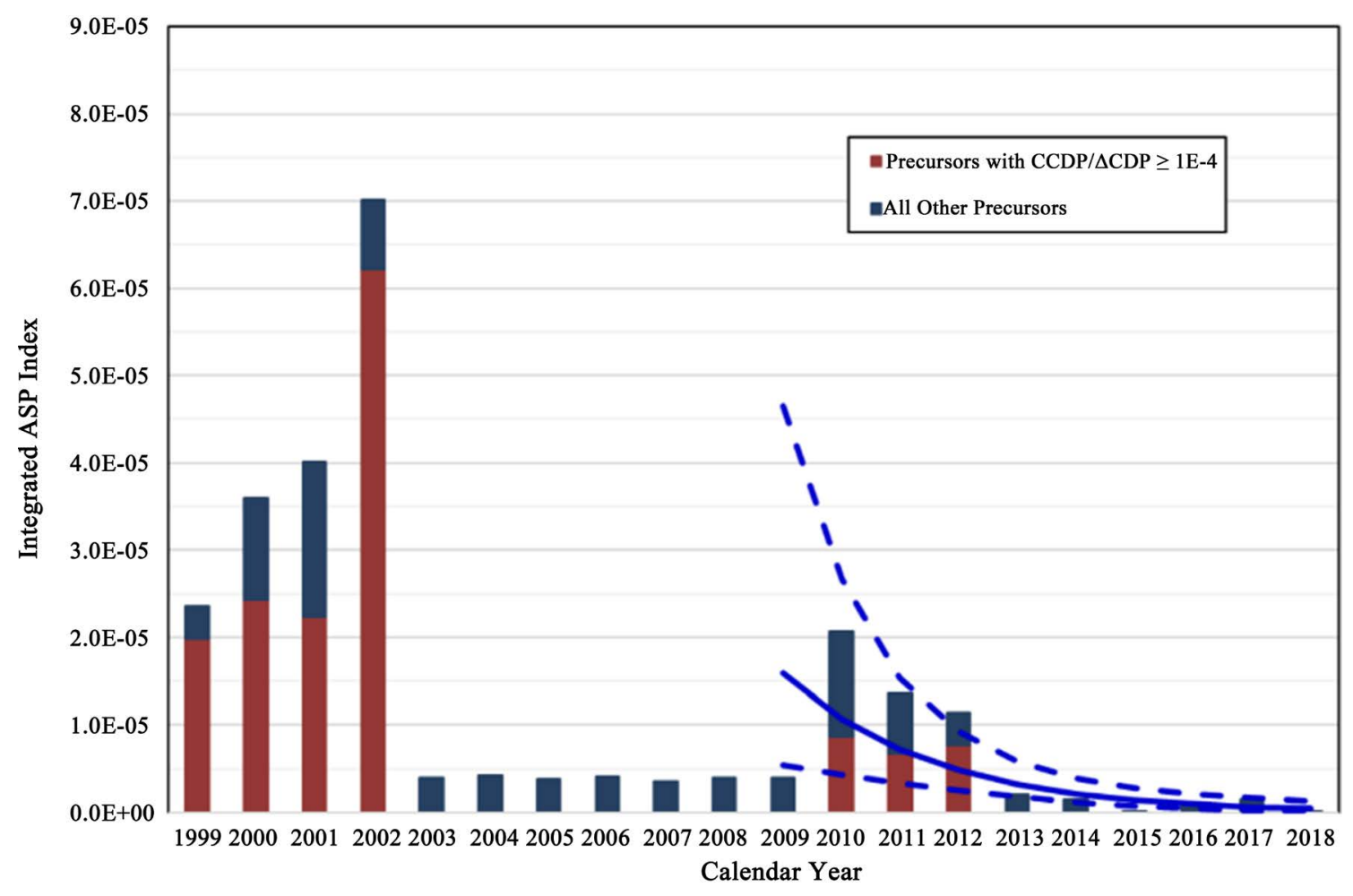

Figure 2. USNRC integrated ASP index trend [16].

estimate for the US fleet is in the order of magnitude of $10^{-5}$ per reactor-year, which is similar to the PSA estimates. Moreover, it shows a decreasing trend representing plant retrofits and improved safety considerations. Some researchers [17] [18] are developing methods to generalize these calculations to worldwide operating fleets and compute representative CDF estimate, using generic PSA models applied to a sufficiently large sample of worldwide precursors and safety significant events.

The other issue of concern, when discussing the safe operation of nuclear power plants, is radioactive waste burden. To start with, LWRs follow one of three fuel cycle concepts, "once-through", "partially closed" and "fully closed" [4]. All start with uranium mining, enrichment to $3 \%-5 \%$, and fabrication of uranium dioxide fuel pellets to be loaded in fuel rods and elements. The spent fuel (SF) is then unloaded and stored in a water pool for several months to cool down to sufficiently low levels. In the once-through cycle, SF is sent for extended storage, pending conditioning and emplacement in permanent disposal facilities such as deep geological repositories. On the other hand, SF can be reprocessed to extract fissile and other usable material such as uranium and plutonium before disposal (partially closed cycle). In the fully-closed fuel cycle, uranium, plutonium, and other minor actinides (long-lived radionuclides) are extracted and used as fuel in advanced fast reactors, hence significantly reducing the amount of long-lived radioactive waste to be disposed.

The different fuel cycles concepts have advantages and disadvantages, notably in terms of non-proliferation issues; the once-through fuel cycle is the most fa- 
vorable as no separation of fissile material, $\mathrm{Pu}$ in particular, takes place. However, this means that large volumes of high-level radioactive wastes will have to be disposed. In contrast, closed fuel cycle concepts are more vulnerable in terms of proliferation. However, they allow for better exploitation of fuel reserves, and bring down nuclear waste volumes to manageable amounts with low radiotoxicity levels [4].

In all fuel cycle concepts, a safe and long-term disposal of radioactive wastes is required, and the deep underground storage-mainly for high and intermediate level waste-seems to be the most promising and favorable option by countries and the public [19]. However, due to the inherent uncertainties, strong opposition, and strict regulatory and safety requirements, the advancement in licensing and operation of repositories are still slow, and there is no operating deep geological repository around the world yet; nuclear waste is currently stored on site or in dedicated interim storage facilities. Nevertheless, enormous work and research are ongoing to address the underlying uncertainties over the large geological time scales and push forward the development of safe and passive deep geological repositories [20] [21] [22] [23]. Finland is in the lead, granting the license and starting the construction at Olkiluoto site in 2015 with the disposal process expected to start by 2024 . Sweden has submitted its license application in 2011 and is waiting for a final approval by the authorities. Other countries like France, Switzerland, Canada, and US are also pushing forward in this direction, investigating appropriate sites and preparing their license applications [24].

Major accidents and public concerns have triggered significant improvements, either by retrofitting existing plants, or by evolutionary new reactor design concepts. Retrofits such as additional emergency power, mobile pumps, bunkered equipment for flooding protection, and others have been introduced. Furthermore, with the advanced Gen III reactors, improvements in the lifetime, fuel technology, thermal efficiency, and safety features are achieved. A prominent example is the European Pressurized Reactor EPR, having advanced active safety features and severe accident mitigation systems such as [25]:

1 ) increased reliability (four $100 \%$ redundant safety systems, CDF $2 \times 10^{-6}$ per reactor-year),

2) fully digitalized instrumentation and control systems,

3) extended grace periods,

4) core catcher, advanced containment systems (passive hydrogen recombiners, dedicated containment heat removal system).

Moreover, the so-called revolutionary Gen III+ reactors such as the AP-1000 have pushed systems' reliability forward while incorporating the concept of passive safety. Some of these advanced reactor designs have already been in operating since a few years, and others are under construction with some delays. Further safety improvements and innovative design concepts are required-and some are on the way-to ensure that the nuclear civil industry avoids high-consequence accidents and extremely long stewardship times of long-lived fission products and 
actinides.

\section{Key Requirements for Innovative, Less Vulnerable Nuclear Systems Design}

We should not overburden the use of nuclear energy with an impossible "zero risk" expectation. However, there are major barriers to make its future, potentially expanded, use acceptable to the public. These barriers include the unequal treatment of (i) probabilities of the extraordinarily high potential consequences, should a severe accident happen, and (ii) the perceived cancer dread of even low doses of radiation, in particular. To overcome these barriers, we recommend a fundamental shift from reactor designs that depend on properly designed (active) safety systems, requiring AC power and reliable actuation mechanisms, towards designs that incorporate passive and inherent safety features. Furthermore, nuclear plants should be less sensitive to adequate protection against natural events and malicious man-made physical and cyber-based attacks and should warrant higher tolerability to human errors, lack of safety culture and socio-political instability within the operational environment. The following more specific requirements, aiming as far as possible at a deterministic exclusion of serious conditions and states, are put forward (see [4], p. 187-8), all where appropriate:

1) Control of nuclear reactivity and elimination of potential reactivity induced accidents by reactor core design or at least controllability by passive means; this can be achieved by:

a) weak, negative reactivity coefficients (graceful reaction on increasing fuel temperature, power, void fraction, burn-up),

b) small reactivity surplus at startup with fresh fuel,

c) fail-safe design of shutdown absorber rods.

2) Assurance of heat removal to ultimate heat sink and retention of fission products, i.e. forgiveness against loss of active core cooling; this can be achieved by:

a) low power density and power size (to avoid exceeding critical temperature limits),

b) strategies to avoid high fission product inventory, e.g. by dispersed fuel,

c) temperature resistant fuel cladding and structural material that will not melt or burn, if adverse conditions occur,

d) sufficient heat storage capability and inherent/passive heat transfer mechanisms in case of loss of normal (forced) cooling/control of coolant inventory (depressurization)/total loss of power,

e) passive decay heat removal systems.

3) Securing structural integrity to avoid geometric disorders (e.g. loosing core cooling capability) or loss of confinement of radioactive inventory; this can be obtained by:

a) low primary circuit pressure or leak/rupture proof components (reactor 
pressure vessel),

b) radiation resistant and chemically and physically robust core structures,

c) underground siting for protection against extreme external impact, including conventional weapons' attack.

4) Use of chemically non-reactive, non-toxic materials and fluids or avoid direct contact of reacting substances; this can be achieved by intermediate cycles, if necessary.

5) Avoidance/incineration of long-lived radioisotopes (actinides) by fuel cycle designs allowing for reduced long-term stewardship (husbandry times); this can be achieved by:

a) a switch to thorium with drastically smaller generation of long-lived minor actinides,

b) waste burner core designs,

c) striving for enhanced closed fuel cycles or for long-term stable, high burn-up spent fuel as an open fuel cycle option.

6) Enhanced intrinsic proliferation resistance characteristics of the fuel, entire fuel cycle and related processes; based on the discourse on proliferation issues, the following principles, means and strategies can be assigned and should be applied:

a) avoid use of highly enriched uranium (HEU),

b) configure nuclear reactors to enable maximum burn-up of fuel and thereby decrease the amount of plutonium in spent fuel that could be used for weapons,

c) avoid high-grade plutonium generation, e.g. by employed blankets,

d) reprocess spent fuel only if there is a clear plan to minimize the time during which weapons-grade material, notably plutonium, is in separated form and to reuse it as soon as feasible, to avoid accumulating a stockpile,

e) strive for online reprocessing including fuel fabrication at the reactor location and avoid transportation of sensitive material,

f) implement protective measures throughout the entire fuel cycle.

\section{Candidate Design Features and Revolutionary New Technology Options}

In this section, we will discuss and analyze crucial design features for advanced reactors that aim at meeting the key requirements, outlined before. Table 1 presents advantages and disadvantages of the different operating neutron spectra and different potential coolants.

Other design variables that could be also revisited are power densities and power levels, different fuel material and designs, and fuel cladding. Power densities can range from about $70 \mathrm{MW} / \mathrm{m}^{3}$ for typical LWR, and can be as high as 290 $\mathrm{MW} / \mathrm{m}^{3}$ for sodium cooled fast reactors, depending on different heat transfer capabilities, coolant properties, structural materials, and others. Besides, power levels can range from few tens of MWe for small-modular reactors (SMR) and can reach more than a thousand MWe (e.g. 1600 MWe for large size LWR). The 
Table 1. Advantages and disadvantages of different designs features [4].

\begin{tabular}{|c|c|c|c|}
\hline \multicolumn{2}{|c|}{ Design Features } & \multirow{2}{*}{$\begin{array}{l}\text { Advantages } \\
\text { - large fission to absorption ratio } \\
\text { - minimize radioactive waste formation } \\
\text { - burnup extension } \\
\text { - sustainability (breeding) }\end{array}$} & \multirow{2}{*}{$\begin{array}{l}\text { Disadvantages } \\
\text { - potential for disruptive power excursions } \\
\text { - low margin to prompt criticality (Pu-239 } \\
\text { compared to U-235) }\end{array}$} \\
\hline $\begin{array}{l}\text { Neutron } \\
\text { spectrum }\end{array}$ & Fast & & \\
\hline & Thermal & $\begin{array}{l}\text { - robust reactivity against fluctuations in physical parameters } \\
\text { - safer margin to prompt criticality } \\
\text { - long operational experience }\end{array}$ & $\begin{array}{l}\text { - inefficient fuel exploitation } \\
\text { - larger radioactive waste formation }\end{array}$ \\
\hline \multirow[t]{4}{*}{ Coolant } & Sodium & $\begin{array}{l}\text { - superior thermal hydraulic properties/heat transfer } \\
\text { characteristics } \\
\text { - excellent neutronic properties and economy } \\
\text { - good compatibility with structural materials }\end{array}$ & $\begin{array}{l}\text { - } \text { significant reactivity insertion issues (sodium } \\
\text { boiling, large coolant temperature coefficient) } \\
\text { - high chemical activity with water, steam, and } \\
\text { air (explosion risk) } \\
\text { - optical opacity }\end{array}$ \\
\hline & Lead & $\begin{array}{l}\text { - good natural circulation and heat transfer properties } \\
\text { - superior neutronic characteristics and performance } \\
\text { - chemically inactive } \\
\text { - low cost (lead is abundant) }\end{array}$ & $\begin{array}{l}\text { - high melting point (freezing potential) } \\
\text { - erosion and corrosion potentials (need for } \\
\text { coating) } \\
\text { - Polonium-210 activity build up } \\
\text { - optical opacity }\end{array}$ \\
\hline & $\begin{array}{l}\text { Molten Salt } \\
\text { (fluorides or } \\
\text { chlorides) }\end{array}$ & $\begin{array}{l}\text { - high density-specific heat product (large grace period) } \\
\text { - high boiling temperatures (no void reactivity insertions) } \\
\text { - chemically inactive } \\
\text { - optical transparency }\end{array}$ & $\begin{array}{l}\text { - high melting point (freezing potential) } \\
\text { - neutronically challenging } \\
\text { - small thermal conductivity limiting the power } \\
\text { density } \\
\text { - pumping constraints (large viscosity) }\end{array}$ \\
\hline & $\begin{array}{l}\text { Inert Gas (e.g. } \\
\text { Helium) [26] }\end{array}$ & $\begin{array}{l}\text { - high breeding ratio } \\
\text { - small void reactivity coefficient } \\
\text { - chemically inactive (inert) } \\
\text { - no corrosion/material challenges } \\
\text { - optical transparency } \\
\text { - potential for direct Brayton cycle (lower capital costs) }\end{array}$ & $\begin{array}{l}\text { - high neutron leakage } \\
\text { - relatively poor heat transfer characteristics } \\
\text { - water ingress concerns (positive reactivity } \\
\text { insertions) }\end{array}$ \\
\hline
\end{tabular}

advantages of small power densities and small power ratings mainly lie in the increased robustness against loss of decay heat removal accidents and having more grace periods while staying away from critical temperatures. On the other hand, large power levels and densities benefit from the economy of scale, and have less environmental footprints, as they require less land use per MWe. Moreover, large reactors suit better the needs of mega-cities and centralized hubs. However, from the downside, higher density units are more susceptible to loss of decay heat removal accidents.

When it comes to the fuel, uranium (U-235) is the mostly utilized fissile element in commercial nuclear power plants. As said before, total reserves are estimated to be around 15.9 million tons, enough for 254 years of operation with the current rate of consumption. Taking all possibilities into account, the availability of nuclear energy could be extended for thousands of years [10]. Moreover, 
thorium (namely Th-232) is becoming a fashionable promising fuel option, for which all uranium fuel cycles apply, and having many attractive properties. Thorium is three to four times more abundant than uranium and has superior physical properties in metallic and oxide states (high melting points, high thermal conductivity, small expansion coefficient). It has more specific energy (200 times more than natural uranium), and produces less nuclear wastes with shorter lifetimes [27]. Th-232 is fertile, and has no naturally fissile isotope, it does not undergo fission itself but, on capturing a neutron, it leads to uranium-233 as final product of the reaction chain, which is fissile. It could be misused for weapon production and. as its forerunner Pa-233 can be separated effectively, the Th-232 fuel is not proliferation proof. Thorium-based technologies are still at early phases with little commercial experience, therefore significant investments are still needed (testing, licensing).

Current commercial fuels are based on metal oxide ceramics (UO2), which enjoy high melting point $\left(2850^{\circ} \mathrm{C}\right.$ for $\left.\mathrm{UO} 2\right)$, yet suffer low thermal conductivities. Pure metal fuels include pure uranium or uranium alloys and have very high-if not the highest-fissile atom density, and high heat conductivity, but suffer from low melting points $\left(1133^{\circ} \mathrm{C}\right)$. Non-oxide ceramic fuels have the advantage of high heat conductivities and melting points $\left(2700^{\circ} \mathrm{C}-2800^{\circ} \mathrm{C}\right)$, however, they are more prone to swelling than oxide fuels. Uranium carbide fuel have high thermal conductivity and high melting point, and are considered interesting candidates for some Gen IV reactors. Dissolved liquid fuels offer an inherently stable self-adjusting reactor dynamics and rapid drain ability into dump-tanks [4]. Finally, fuel cladding is another design variable that can be optimized. A huge program on accident tolerant fuel (ATFs), coordinated by Westinghouse, is working on high temperature resistant fuel (enriched U3SiC fuel pellets), and focus on protecting claddings from oxidation by coating.

In what follows, we introduce some new/exotic reactor designs that are at different stages of development. One of the prominent reactor concepts is Generation IV fast breeder reactors. They enjoy a high neutron economy that allows them to breed more fissile fuel than they consume using fast neutrons. Most of their proposed designs can use thorium, natural uranium, or spent fuel from LWRs, hence closing the fuel cycle and increases the utilization of uranium by at least 60 times compared to current LWR [28]. The new concepts claim to be inherently safe and highly resistant to proliferation. Fast breeder projects, which are followed with great interest, include: PRISM, BREST-OD-300, SWaB as well as a novel sub-critical accelerator-driven system (ADS) named MYRRHA [4]. PRISM (Power Reactor Innovative Small Module) is a sodium-cooled fast breeder reactor designed by GE Hitachi Nuclear Energy, and uses spent nuclear fuel from LWR [29]. The design comes with two reactor modules, each having a 311 MWe power output. PRISM is in an advanced stage of development with deployment aims by 2026 [30]. BREST-OD-300 is a 300 MWe Russian lead-cooled 
fast breeder reactor. It is a pool-type reactor equipped with passive safety systems and uses spent nuclear fuel. The reactor is in an advanced stage and construction was approved in 2016, with the plant expected to be finished by 2026 [31]. SWaB (Seaborg Waste Burner) is a proposed molten salt reactor design by the Danish company Seaborg Technologies [32]. The molten salt used in this modular reactor will be a combination of spent nuclear fuel and thorium. The design is still in a very early stage of development. A novel concept currently in development by the Belgian Centre for Nuclear Research (SCK CEN) is the sub-critical accelerator-driven system (ADS) named MYRRHA (Multi-purpose Hybrid Research Reactor for High-tech Applications). This unique design couples a lead-bismuth fast reactor with a proton accelerator and is intended to function as an actinide burner (transmutation process). The reactor has a budget of 1.6 billion Euros and is scheduled to be commissioned by 2036 [33]. More details regarding these reactor concepts, characteristics, and key parameters are presented in Table 2.

Moreover, there is a revival of interest in small and simpler units for electricity production and other purposes. The incentive to develop advanced small (up to $300 \mathrm{MWe}$ ) modular reactors (SMR) comes from different sources. There is a strong belief [34] [35] [36] that SMRs would:

- open additional market sectors, e.g. heat production for chemical processes or seawater desalination, and, based on enhanced safety and security characteristics, allow for site flexibility, e.g. sites closer to consumers which are not accessible to large reactors;

- better adapt to low growth rates of energy demand and provide power away from large grid systems, often found in small or developing countries, and are more suitable to replace aging fossil-fired plants;

- lower requirement for access to cooling water and land, the latter comparing favorably with respect to wind and solar energy;

- lower upfront capital cost and lead to easier financing and earlier revenues;

- better meet specific user requirements, mostly in relation to safety by design incorporating reduced core inventory/potential source term, enhance safety performance through a high level of passive and/or inherent safety features and allow for underground construction for enhanced security and protection against external hazards including seismic, all that would hopefully help to improve public acceptance;

- allow for greater simplicity of design and modularization, enabling economy of serial production largely in factories, shipping to utilities and site-assembling, going along with potential usage of domestic resources;

- enable implementation of higher quality standards and shorter construction times;

- add ability to remove reactor modules or facilitate in-situ decommissioning at the end of lifetime.

Some argue that SMR facilitate a wider spread of nuclear energy, i.e. to newcomer 


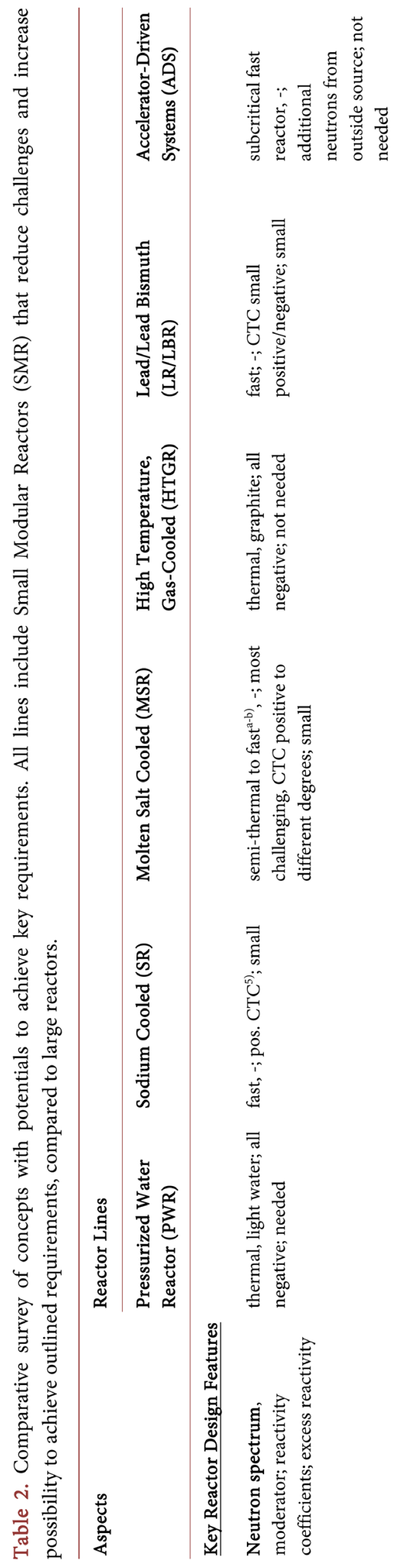

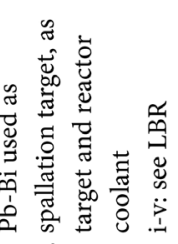

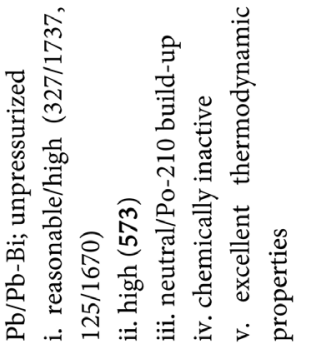

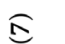

苋 总高

$\sqrt{1+1}$

then
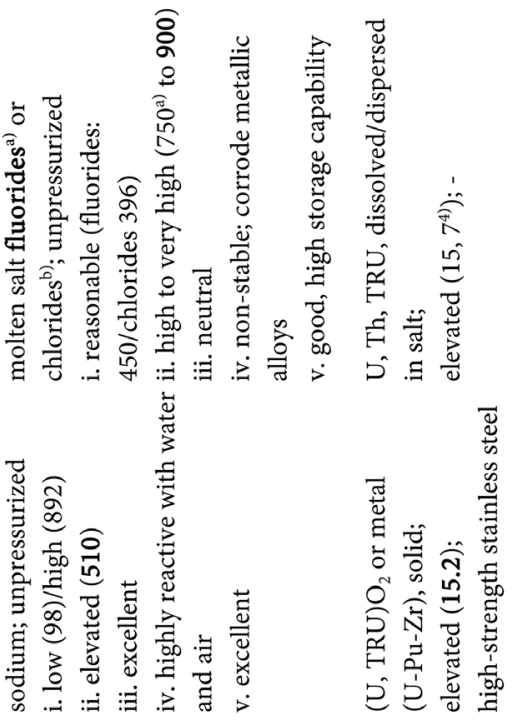

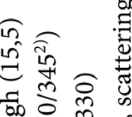

s0

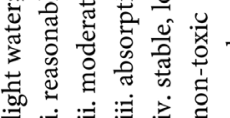

些.

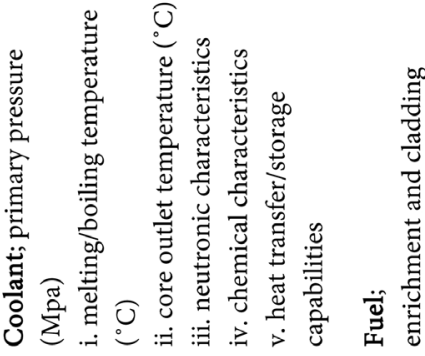

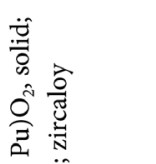

已商

今)

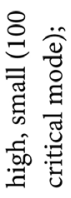

葛

苛苛弯

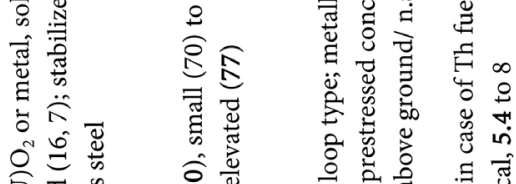

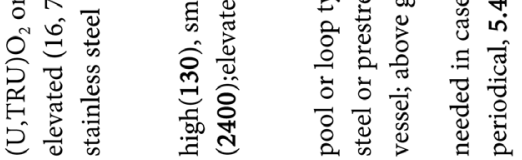

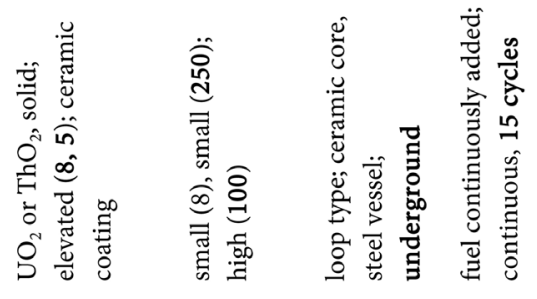

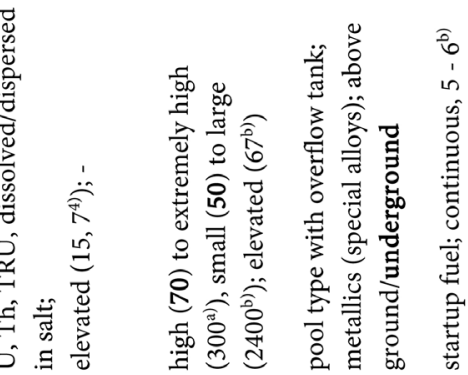

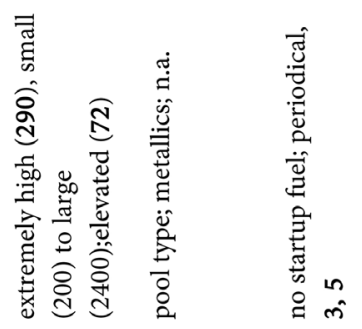

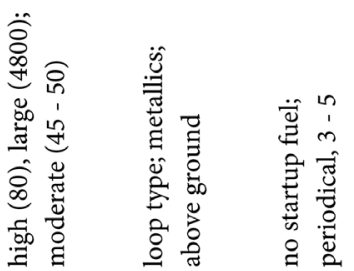

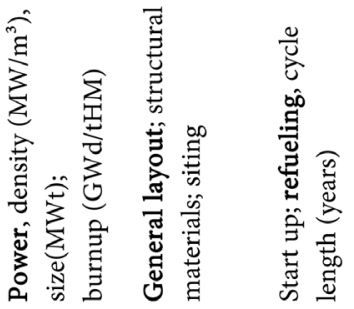




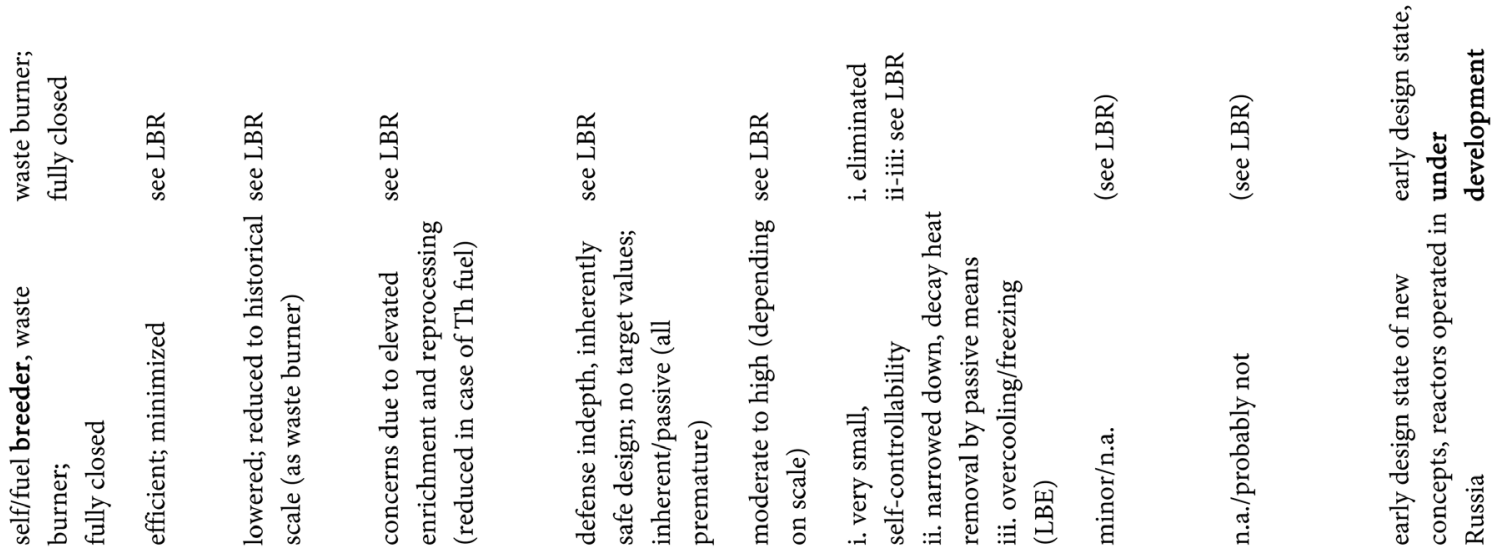

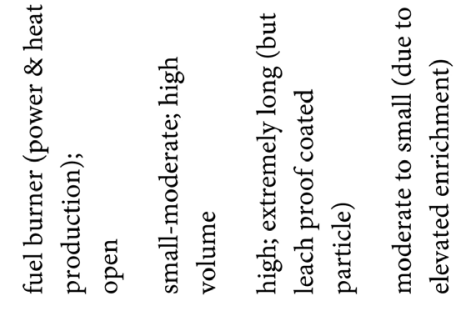

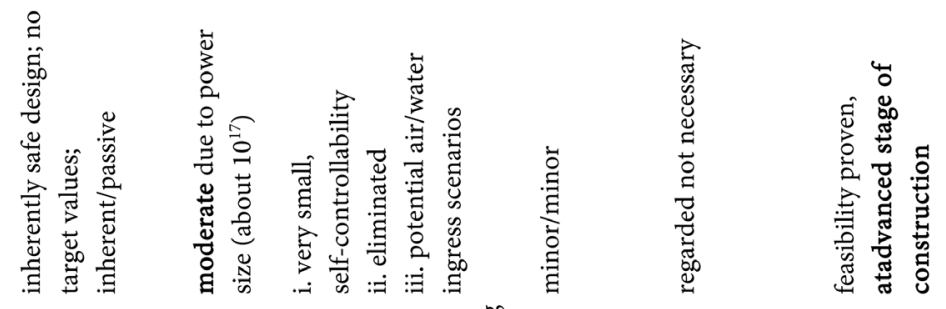

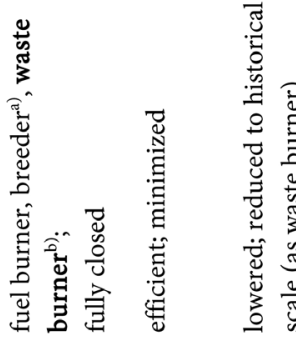
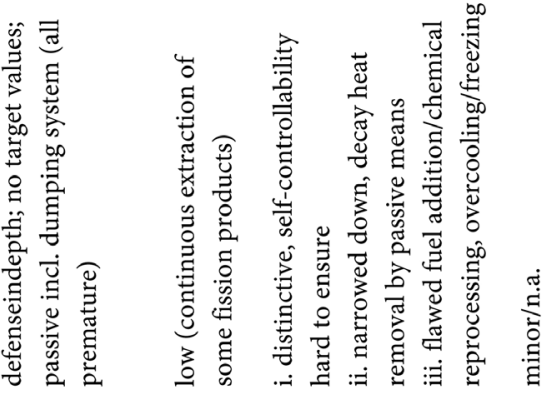

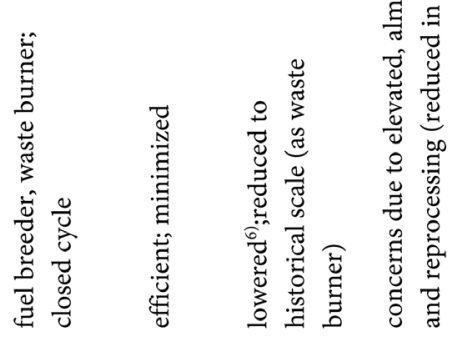
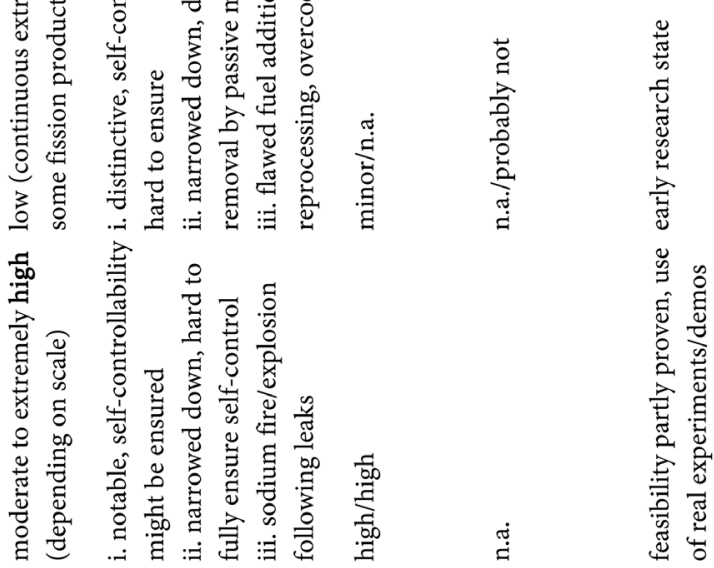

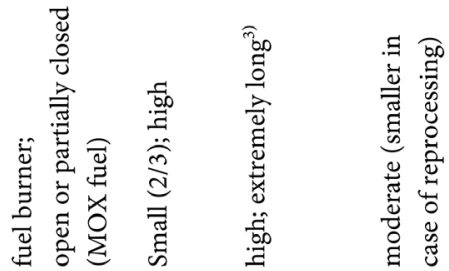

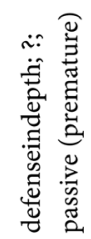

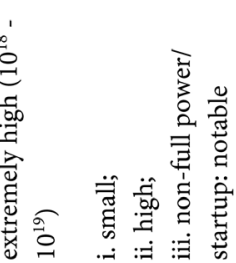
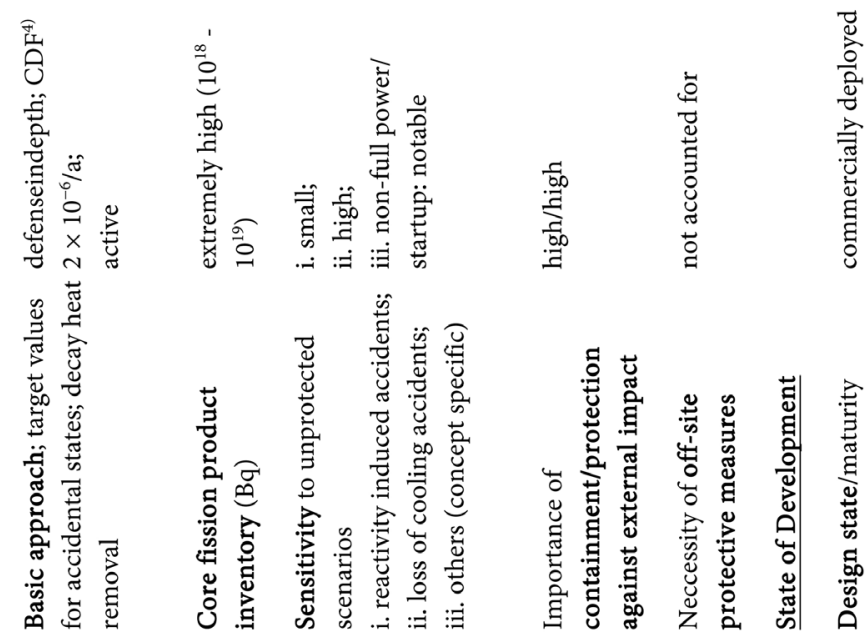


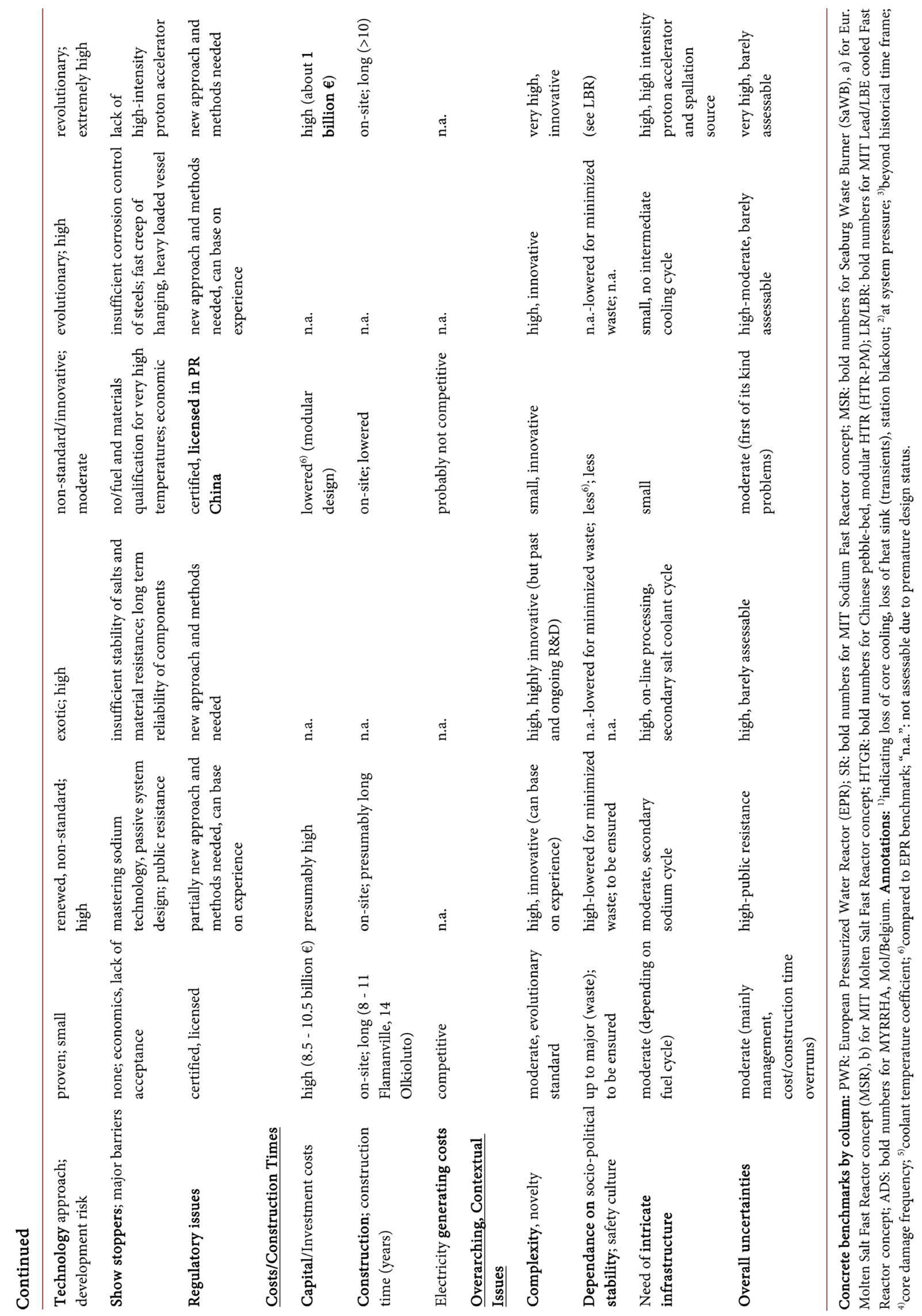


States, and make easier the build up a domestic nuclear infrastructure and capabilities, and even foresee a hybrid energy system with integration of SMR and renewables.

All types of large reactors currently in use or being developed are represented in the SMR lines, including thermal neutron spectrum water-cooled reactors, various kinds of fast neutron spectrum reactors (FR) including liquid metal and temperature molten salt cooled reactors, and gas-cooled, graphite moderated high reactors (Figure 3). LWR-based SMR has the lowest technological and regulatory risk, while some fast SMR concepts enable longer operation before refueling, which is regarded advantageous, where appropriate. However, some question the economic competitiveness of SMR and raise concerns regarding adequacy of the current regulatory system and licensability of some (first-of-its-kind) designs.

A promising SMR reactor design that enjoys interesting inherent safety features is the HTR-PM, or the high-temperature gas-cooled pebble-bed modular reactor. HTR-PM is a generation IV thermal reactor utilizing multi-layered spherical fuel elements (TRISO coated particles) which act as a barrier against fission product escape. The design comes with two reactor modules each having $250 \mathrm{MW}$ thermal power, connected to a single $210 \mathrm{MWe}$ turbine. The HTR-PM demonstration plant is in advanced stage of construction in the Shindao Bay, Shandong area in China, and is expected to be operational soon [37].

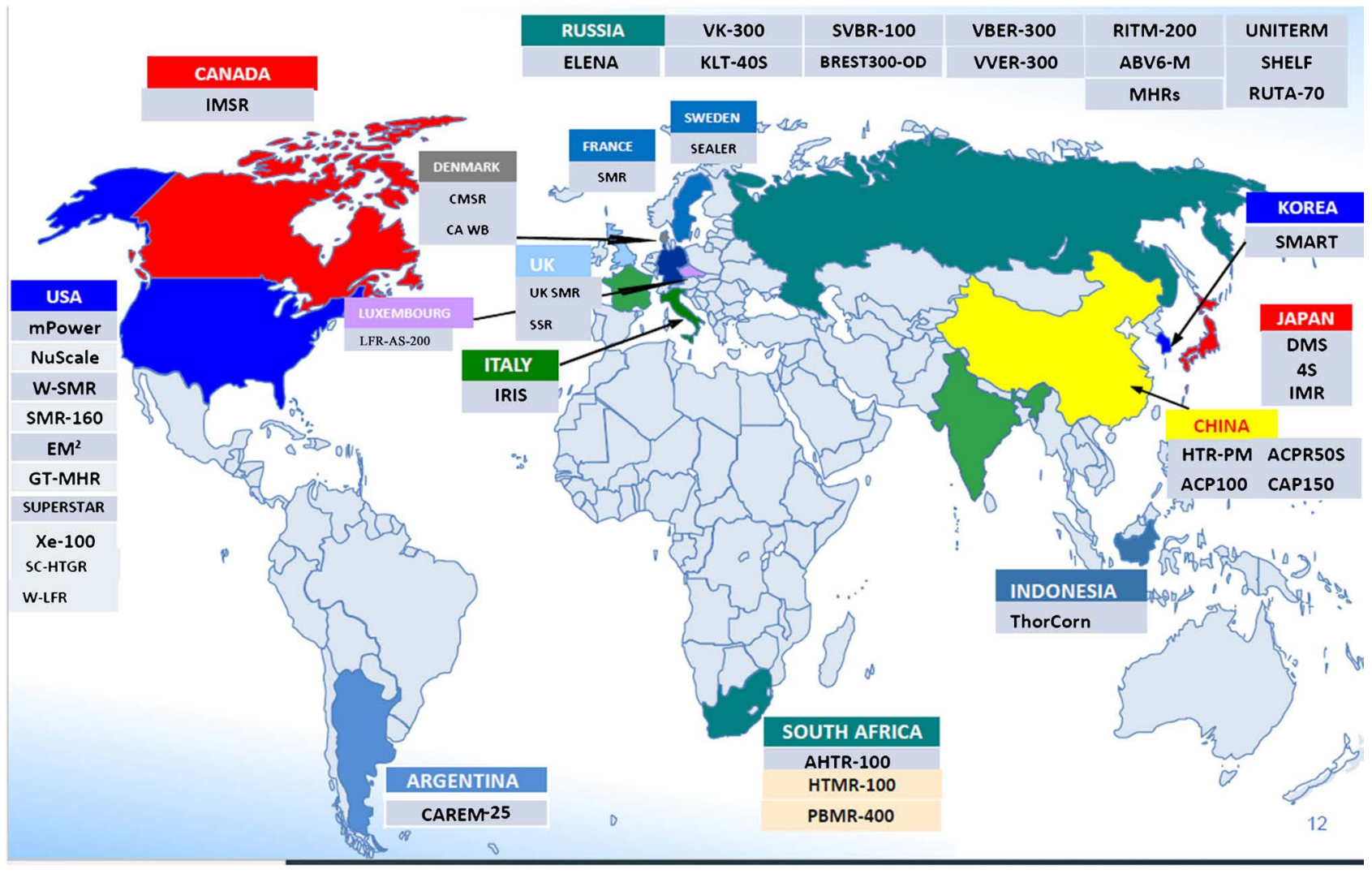

Figure 3. Worldwide development of small and medium sized modular reactors [36]. 
After commissioning, the HTR-PM will be the first operable generation IV reactor in the world.

Other interesting concepts include the floating SMRs, which can be built at shipbuilding facilities and towed to the designated areas where they could provide electricity, district heating and seawater desalination. These features could be notably important for power-hungry developing countries undergoing industrialization. Currently, there is one operating floating nuclear power plant in the world, the Akademik Lomonosov, which was commissioned in December 2019 in Russia [38]. The plant consists of two 35 MWe PWRs, which are based on the KLT-40 marine propulsion reactors. These reactors operate in the thermal neutron spectrum using $14.1 \%$ enriched uranium and employ a combination of passive and modernized active safety systems [39].

\section{Concept by Concept Comparison and Assessment against Key Requirements}

After presenting different novel reactor concepts that try to fulfill the key requirements of Section 4, we try here to make a concept-by-concept comparison between the different technologies. The results indicate a high potential for far-reaching improvements compared to the most advanced existing LWRs. Table 3 shows a ranking of the presented Gen IV reactors against key safety criteria detailed in section 4, compared with the Gen III+ large EPR. As can be

Table 3. Ranking from excellent (5) to neutral to very poor (1) of Gen IV reactors against key safety criteria-with the Gen III EPR as the benchmark.

\begin{tabular}{|c|c|c|c|c|c|}
\hline \multirow[b]{2}{*}{ Key requirements } & \multicolumn{5}{|c|}{ Candidate reactor concepts-varying coolant, selected designs in brackets } \\
\hline & $\begin{array}{l}\text { Water-thermal } \\
\text { (large EPR) }\end{array}$ & $\begin{array}{l}\text { Sodium-fast } \\
\text { (PRISM) }\end{array}$ & $\begin{array}{l}\text { Molten Salt-fast } \\
\quad(\text { SaWB })\end{array}$ & $\begin{array}{l}\text { Helium-thermal } \\
\text { (HTR-PM) }\end{array}$ & $\begin{array}{c}\text { Lead-fast } \\
\text { (BREST-OD-300) }\end{array}$ \\
\hline Elimination of Reactivity Induced Accidents & 4 & 2 & 1 & 5 & $2-3$ \\
\hline Resistance to Loss of Active Core Cooling & 1 & 2 & 3 & 5 & $2-3$ \\
\hline - avoid exceeding critical temperatures & 1 & n.a. & n.a. & 5 & n.a. \\
\hline - avoid high fission product inventory & 1 & $4^{1}$ & $5^{2}$ & $4^{1}$ & $4^{1}$ \\
\hline - provide sufficient heat storage $\&$ transfer capacity & 4 & 5 & 4 & 4 & 5 \\
\hline Structural Integrity & 2 & 4 & 4 & 5 & 4 \\
\hline $\begin{array}{l}\text { - avoid high operating pressure } \\
\text { [suitability of underground siting] }\end{array}$ & $1[2]$ & $4^{3}[5]$ & $5[5]^{4}$ & $4[5]^{4}$ & $4^{3}[4]$ \\
\hline $\begin{array}{l}\text { Use Non-chemically Reactive/Non-Toxic } \\
\text { Materials }\end{array}$ & 4 & $1^{5}$ & $2^{5}$ (non-stable) & 5 & 4 \\
\hline Avoid Long-lived Radioisotopes & 1 & 4 & 5 & 4 & 5 \\
\hline Enhance Proliferation Resistance & 4 & 2 & 2 & 3 & 2 \\
\hline - avoid high enriched uranium & 5 & $2^{6}$ & $2^{6}$ & $2-3$ & $2^{6}$ \\
\hline
\end{tabular}

${ }^{1}$ Due to small power size; ${ }^{2}$ in case of dispersed fuel \& due to small power size; ${ }^{3}$ not pressurized but high static load; ${ }^{4}$ foreseen; ${ }^{5}$ intermediate cycle (IHX) foreseen; ${ }^{6}$ close to HEU lower limit. 
seen, none of the best versions, i.e. small sized in general, of the candidate concepts meet all requirements convincingly, yet. Thermal helium cooled reactors (HTR-PM) come closest, promising inherent robustness against classical severe accidents and largely avoiding long-lived radioisotopes when using thorium fuel; they are however not capable of burning waste. With respect to burning waste, molten salt fast reactors promise to do best but appear most susceptible to reactivity-induced accidents, as are all liquid metal cooled fast reactors, albeit to different degrees. There is also a potential of new concept specific accidents, such as overcooling/ freezing of coolant, chemical reactions following coolant out-flows after leaks or air/water ingress into hot graphite cores, which deserve special attention. Thus, future research and development appear necessary, aiming at further improving some essential characteristics and features and/or combining design elements in a radically new and innovative way. All concepts seem to have limited capabilities to achieve the goal of reducing proliferation risk or even to maintain the current level, mainly due to partially elevated and/or significantly increased enrichment needed for reprocessing.

It is also important to note that revolutionary designs and technologies often introduce new man-machine interfaces, lack experience, and tend to represent a jump in complexity. The molten salt cooled systems with dissolved fuel, fission products, and off-gas systems may serve as example; some features of coolants, e.g. production of activation products, chemical toxicity, non-transparency, freezing at high temperatures, may require complex operations and maintenance procedures ([5], p. 69). All this may also present regulatory barriers since the regulators need to assess unfamiliar technologies. This calls for unprecedented excellence in research, development, design, and for adequate funding.

Historically, public funding for civil nuclear research, development, and demonstration (RD\&D) has contained the highest share of the total budget for energy RD\&D in OECD countries until 2009 (Figure 4(a), Figure 4(b)). Since then, it was overtaken by the combined budget for renewable energy sources (wind, solar, small hydro), research in fuel cells, hydrogen and other power and storage technologies (Ren + FC + P \& S respectively) [40]. The share has been on the decline for 30 years, from having $75 \%$ of the total energy RD\&D funding in 1974, to approximately $20 \%$ in 2013. In the more recent years, the investments in civil nuclear research in OECD countries are slowly increasing, stabilizing their share at $22 \%$ of the total energy technology RD\&D budget. This increase is mainly due to a revised strategic view in the USA on nuclear power as a viable and affordable low carbon footprint power, especially with the future application of advanced reactor designs.

In the USA, the $2019 \mathrm{RD} \& \mathrm{D}$ budget for nuclear energy was $\$ 1.3$ billion, including $\$ 100$ million for the research of advanced SMR and $\$ 112$ million for Advanced Reactor Technologies [41]. The budget for 2020 was increased by $13 \%$ to $\$ 1.5$ billion, out of which $\$ 230$ million are allocated for a program focused on the "construction of real demonstration reactors that are safe and affordable (to 
(a)

Total Budget

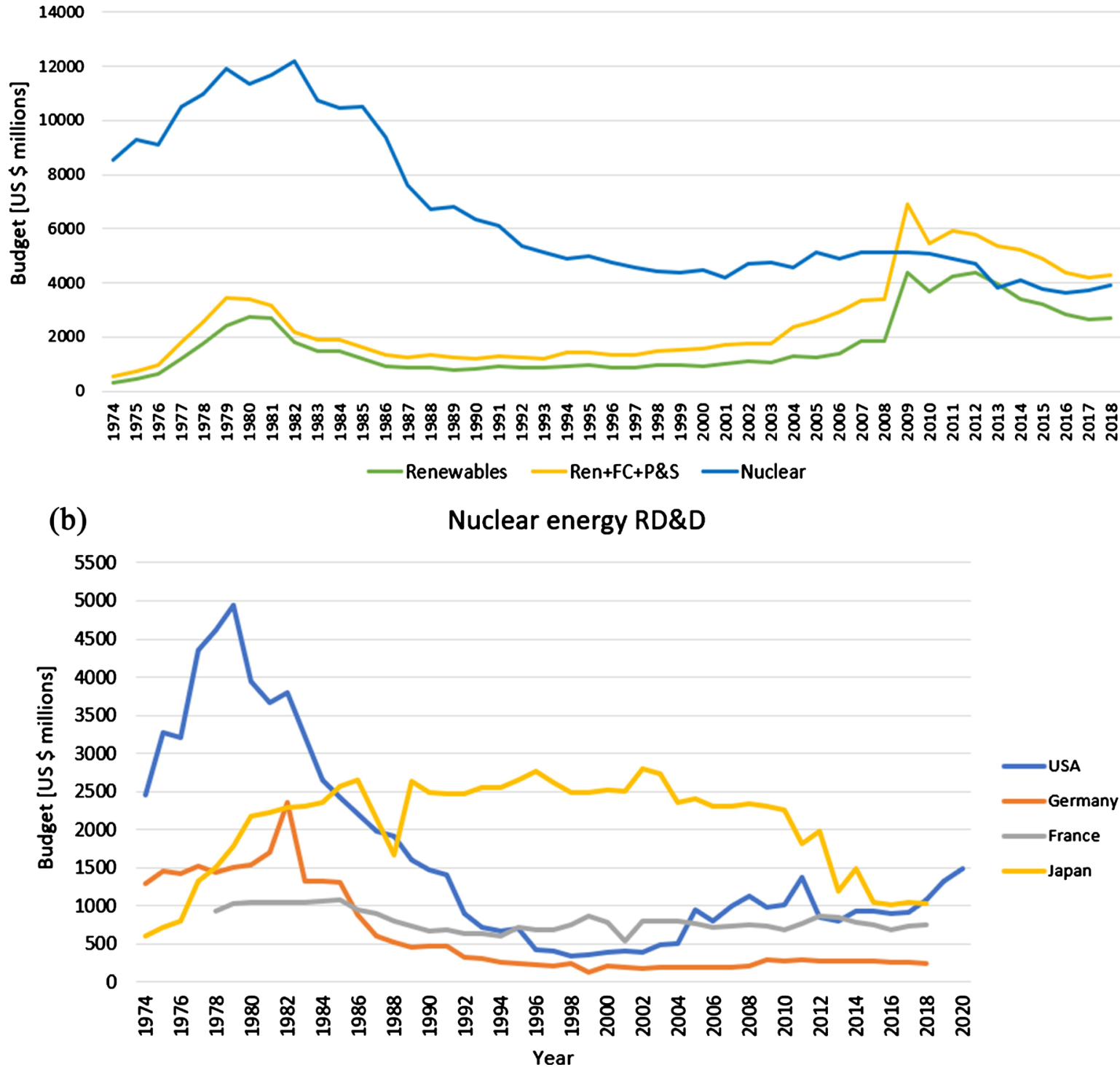

Figure 4. Total budget for RD\&D over time per type of technology (a) and countries (b), in millions of US dollars in their value in 2018 (adjusted for inflation).

build and operate) in the near and mid-term" [42]. Two demonstration projects are set to begin this year, where the program will support at least $50 \%$ of the costs, the remainder to be provided from the private sector. This program will also support the Nuclear Regulatory Commission (NRC) in evaluating safety issues and technical challenges unique to advanced reactors and their licensing. Other OECD countries (e.g. France, UK) have also increased their research in nuclear power in recent years, as well as Russia and China, which have invested heavily in the development of advanced reactor designs.

\section{Concluding Remarks}

There is a growing demand in electricity production due to its increasing use in oth- 
er sectors (e.g. e-mobility, heat, and digitalization) and expanding access to billions of people while simultaneously drastically enlarging the share of de-carbonized generation assets, in particular. With such high stakes, to rely on variable, low-density wind and solar options including necessary infrastructure alone appears a strategic error, disregarding the proven principle of diversity. We argue for keeping the nuclear option open or even for expanding its global use, supported by future revolutionary safe, clean and thus more sustainable nuclear technologies, which would be acceptable to an otherwise presently mostly nuclear-averse society. This proposal is further supported when one acknowledges the real problem of stewardship of already existing high-grade nuclear waste over time scales eclipsing that of stable societies. Novel concepts are portrayed and then assessed against set-up key requirements calling for a shift towards reactor designs that incorporate passive and inherent safety features, use fuel more effectively, avoid or eliminate long-lived actinides, and increase proliferation resistance. The results show a high potential of improvement compared to current designs but further research and development are needed to fully meet those requirements; small modular designs (SMR) of different reactor lines are of special interest.

To realize this vision, substantial ongoing national and international RD\&D programs exist, although funding is still at historically low levels. Moreover, in the nuclear industry, there is the risk of stagnation of essential human capital and know-how. The concepts and designs presented provide the impulse to get us over the existing hurdles, but the scope is ambitious, and time delay from RD\&D to commercial deployment, in general, appears too long especially in the West, stemming in part from regulatory inertia. Therefore, we call for an urgent increase in government and international $\mathrm{RD} \& \mathrm{D}$ funding by the order of a few hundreds of billions of USD per year, for an international civilian "super-Apollo" program. Such a large-scale public program is not unprecedented in size, and experience indicates that such investments in fundamental technologies are not only of immense public benefit but also enable revolutionary innovations to be spun out that would not otherwise ever have been attained.

\section{Conflicts of Interest}

The authors declare no conflicts of interest regarding the publication of this paper.

\section{References}

[1] BP (2019) BP Statistical Review of World Energy 2019. 68th Edition. https://www.bp.com/content/dam/bp/business-sites/en/global/corporate/pdfs/energ y-economics/statistical-review/bp-stats-review-2019-full-report.pdf

[2] OECD-IEA (2019) World Energy Outlook 2019. https://www.iea.org/reports/world-energy-outlook-2019

[3] United Nations, Department of Economic and Social Affairs, Population Division (2016) The World's Cities in 2016-Data Booklet (ST/ESA/SER.A/392). https://www.un.org/en/development/desa/population/publications/pdf/urbanizatio 
n/the_worlds_cities_in_2016_data_booklet.pdf

[4] Sornette, D., Kröger, W. and Wheatley, S. (2019) New Ways and Needs for Exploiting Nuclear Energy. Springer, Berlin. https://doi.org/10.1007/978-3-319-97652-5

[5] Buongiorno, J., Corradini, M., John, P. and Petti, D. (2018) The Future of Nuclear Energy in a Carbon-Constrained World. Massachusetts Institute of Technology, Cambridge, 26.

[6] Greenpeace (2015) The Energy [R]evolution 2015.

http://www.greenpeace.org/international/en/campaigns/climate-change/energyrevo lution

[7] IAEA (2019) Preliminary Nuclear Power Facts and Figures for 2019. https://www.iaea.org/newscenter/news/preliminary-nuclear-power-facts-and-figure s-for-2019

[8] World Nuclear Association (WNA) (2019) World Nuclear Performance Report 2019.

https://www.world-nuclear.org/getmedia/d77ef8a1-b720-44aa-9b87-abf09f474b43/p erformance-report-2019.pdf.aspx

[9] PRIS (2020) Reactors under Construction. https://pris.iaea.org/PRIS/WorldStatistics/UnderConstructionReactorsByCountry.aspx

[10] OECD-NEA and IAEA (2018) Uranium 2018: Resources, Production and Demand. NEA No. 7413. https://www.oecd-nea.org/ndd/pubs/2018/7413-uranium-2018.pdf

[11] EU-New Energy Externalities Developments for Sustainability (NEEDS) (2016) NEEDS Documents 20.10.2016. http://www.needs-project.org

[12] Hirschberg, S. and Burgherr, P. (2015) Sustainability Assessment for Energy Technologies. In: Handbook of Clean Energy Systems, John Wiley \& Sons, Hoboken, 1-22. https://doi.org/10.1002/9781118991978.hces070

[13] Ayoub, A., Stankovski, A., Kröger, W. and Sornette, D. (2020) Proceedings of the 30th European Safety and Reliability Conference (ESREL) and the 15th Probabilistic Safety Assessment and Management Conference (PSAM), Venice, Italy, 1-6 November 2020. (In Press)

[14] Gomez Cadenas, J.J. (2012) Nuclear Power, No Thanks? The Nuclear Environmentalist. Springer, Milano. https://doi.org/10.1007/978-88-470-2478-6_10

[15] Kröger, W. (2005) Risk Analyses and Protection Strategies for the Operation of Nuclear Power Plants. In: Alkan, et al., Eds., Landolt-Börnstein: Numerical Data and Functional Relationships in Science and Technology-New Series, Advanced Materials and Technologies, Nuclear Energy, Springer, Berlin, Chap. 2, 186-235. https://doi.org/10.1007/10857629_12

[16] USNRC (2019) U.S. Nuclear Regulatory Commission Accident Sequence Precursor Program 2018 Annual Report. https://www.nrc.gov/docs/ML1911/ML19119A276.pdf

[17] Ayoub, A., Kröger, W., Nusbaumer, O. and Sornette, D. (2019) Simplified/Harmonized PSA: A Generic Modeling Framework Applied to Precursor Analysis. Proceedings of the 16th International Topical Meeting on Probabilistic Safety Assessment and Analysis, Charleston, 28 April-3 May 2019, 314-320.

[18] Ayoub, A., Kröger, W. and Sornette, D. (2020) Generic Probabilistic Safety Assessment Models for International Precursor Analysis Applications. Proceedings of the International Youth Nuclear Congress (IYNC) 2020, Sydney, 8-13 March 2020.

[19] OECD (2000) Geologic Disposal of Radioactive Waste in Perspective. Paris. https://www.oecd-nea.org/cen/publications/2548-geologic-disposal-rwm.pdf 
[20] Ayoub, A., Pfingsten, W., Podofillini, L. and Sansavini, G. (2020) Uncertainty and Sensitivity Analysis of the Chemistry of Cesium Sorption in Deep Geological Repositories. Applied Geochemistry, 117, Article ID: 104607. https://doi.org/10.1016/j.apgeochem.2020.104607

[21] Medved, I. and Cerný, R. (2019) Modeling of Radionuclide Transport in Porous Media: A Review of Recent Studies. Journal of Nuclear Materials, 526, Article ID: 151765. https://doi.org/10.1016/j.jnucmat.2019.151765

[22] Steefel, C.I. (2019) Reactive Transport at the Crossroads. Reviews in Mineralogy and Geochemistry, 85, 1-26. https://doi.org/10.2138/rmg.2019.85.1

[23] Hansen, C.W., et al. (2014) Overview of Total System Model Used for the 2008 Performance Assessment for the Proposed High-Level Radioactive Waste Repository at Yucca Mountain, Nevada. Reliability Engineering \& System Safety, 122, 249-266. https://doi.org/10.1016/j.ress.2013.06.001

[24] Mikhailova, N. (2019) Developing the First Ever Facility for the Safe Disposal of Spent Fuel. IAEA Bulletin.

https://www.iaea.org/newscenter/news/developing-the-first-ever-facility-for-the-saf e-disposal-of-spent-fuel

[25] Leverenz, R., Gerhard, L. and Göbel, A. (2004) The European Pressurized Water Reactor: A Safe and Competitive Solution for Future Energy Needs. Proceedings of the International Conference Nuclear Energy for New Europe, Portoroz, 6-9 September 2004, 903.

[26] Weaver, K. (2012) Gas-Cooled Fast Reactors. In: Fast Spectrum Reactors, Springer, Boston, 489-511. https://doi.org/10.1007/978-1-4419-9572-8_17

[27] Kiplinger, J.L. and Ramos, O.Jr. (2011) Th-ING: A Sustainable Energy Source. https://www.lanl.gov/science/NSS/issue2_2011/story6full.shtml

[28] Tsvetkov, P., Waltar, A. and Todd, D. (2012) Sustainable Development of Nuclear Energy and the Role of Fast Spectrum Reactors. In: Fast Spectrum Reactors, Springer, Boston, 3-22. https://doi.org/10.1007/978-1-4419-9572-8_1

[29] Tripplet, B.S., Loewen, E.P. and Dooies, B.J. (2010) PRISM: A Competitive Small Modular Sodium-Cooled Reactor. Nuclear Technology, 178, 186-200. https://doi.org/10.13182/NT178-186

[30] Hitachi, G.E. (2018) GE Hitachi and PRISM Selected for U.S. Department of Energy's Versatile Test Reactor Program. https://www.genewsroom.com/press-releases/ge-hitachi-and-prism-selected-us-dep artment-energys-versatile-test-reactor-program

[31] Nuclear Engineering International (2019) Titan-2 Contracted to Build Russia's Brest 300 Reactor.

https://www.neimagazine.com/news/newstitan-2-contracted-to-build-russias-brest300-reactor-7527297

[32] Seaborg Technologies (2015) Seaborg Wasteburner. Molten Salt Reactor. Whitepaper SEAB-WP-2015-001.

http://citeseerx.ist.psu.edu/viewdoc/download?doi=10.1.1.712.5069\&rep=rep1\&type $=\mathrm{pdf}$

[33] MYRRHA Project (2020) MYRRHA Phased Implementation. https://www.myrrha.be/myrrha-project

[34] OECD-NEA Nuclear Development Publication (2016) Small Modular Reactors: Nuclear Energy Market Potential for Near-term Deployment. https://www.oecd-nea.org/ndd/pubs/2016/7213-smrs.pdf 
[35] World Nuclear Association (WNA) (2020) Small Nuclear Power Reactors. https://www.world-nuclear.org/information-library/nuclear-fuel-cycle/nuclear-pow er-reactors/small-nuclear-power-reactors.aspx

[36] Reitsma, F. (2019) The Status of Different SMR Technologies and the Role of the IAEA to Support Its Member States in SMR Technology Development. IAEA Atoms for Peace and Development Presentation.

https://wins.org/wp-content/uploads/2018/11/3.-Frederik-Reitsma_IAEA_SMRs_W INS_Reitsma_5March2019.pdf

[37] World Nuclear News (2020) Key Components of Second HTR-PM Reactor Connected.

https://world-nuclear-news.org/Articles/Key-components-of-second-HTR-PM-reac tor-connected

[38] World Nuclear News (2019) Russia Connects Floating Plant to Grid. https://www.world-nuclear-news.org/Articles/Russia-connects-floating-plant-to-grid

[39] IAEA (2013) KLT-40S. https://aris.iaea.org/PDF/KLT-40S.pdf

[40] International Energy Agency (IEA) (2019) Energy Technology RD\&D Budgets 2019. https://www.iea.org/reports/energy-technology-rd-and-d-budgets-2019\#data-servic e-and-documentation

[41] USA Department of Energy (2018) Final FY19 Appropriations: DOE Applied Energy $R \& D$.

https://www.aip.org/fyi/2018/final-fy19-appropriations-doe-applied-energy-rd

[42] USA Department of Energy (2020) Final FY20 Appropriations: DOE Applied Energy R\&D.

https://www.aip.org/fyi/2020/final-fy20-appropriations-doe-applied-energy-rd 